\title{
Effect of Lifters Shape and Operating Parameters on the Flow of Materials in a Pilot Rotary Kiln : Part I. Experimental RTD and Axial Dispersion Study
}

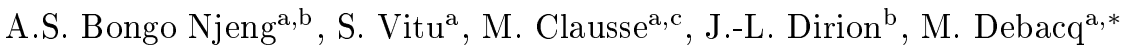

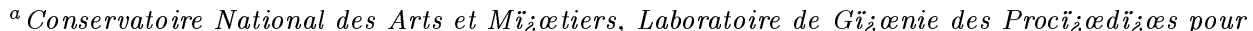 \\ l'Environnement, l'Energie et la Santï $\ddot{z}_{2}$ (EA21), 2 Rue Contï $\ddot{z} \propto, 75003$ Paris, France. \\ ${ }^{b}$ Universiti $i_{\zeta} œ$ de Toulouse, Mines Albi, CNRS UMR 5302, Centre RAPSODEE, Campus Jarlard, \\ F-81013 Albi cedex 09, France \\ ${ }^{c}$ ESIEE Paris, 2 boulevard Blaise Pascal Cit $\ddot{z}_{\dot{2}}$ DESCARTES, BP 99 93162, Noisy le Grand \\ CEDEX, France
}

\begin{abstract}
Experiments on the residence time distribution (RTD) and axial dispersion for the continuous flow of sand and broken rice, through a pilot scale rotary kiln equipped with lifters, are reported. Factors such as the rotational speed, the kiln slope, the materials flow rate and the exit dam height have been studied. Furthermore, two profiles of lifters were used: straight lifters (SL) and rectangular lifters (RL). Thus, under varying conditions the RTDs were obtained by the typical stimulus response test using a tracer and the corresponding axial dispersion coefficients were determined. The validity of the axial dispersion model was assessed in this study, and the model was found to match well with the experimental data. A large number of experiments was conducted, so that, a mathematical model could be developed to predict the axial dispersion coefficient of the solid particles within the kiln. Comparisons with reported models are also discussed. The second part of this study will be concerned with the experimental kiln hold-up and the mean residence time (MRT) of solid particles.
\end{abstract}

Keywords: Rotary kiln, Rotary dryer, RTD, Axial Dispersion, Lifters, Lifting flights

\section{Introduction}

Through the years, rotary kilns, also often called rotary dryers, have become an inescapable benchmark in several industrial sectors. This is because they offer special possibilities regarding the wide range of materials which can be continuously processed with little or no labor to operate, especially when they are under automatic control. As wider are the scopes of applications as wider are the kilns design and size. Rotary kilns range from small cylinders with length-to-diameter ratio (L/iD) below 5 used mostly for mixing granular materials in the pharmaceutical manufacture; medium cylinders with

\footnotetext{
* Principal corresponding author

Email address: marie.debacq-lapassat@cnam.fr (M. Debacq)

Preprint submitted to Powder Technology
}

January 7, 2014 
$\mathrm{L} / \mathrm{iD}$ up to 20 , used for the drying or cooling of solid particles, for instance in the food processing industry when dealing with wet or dry granular materials; and long cylinders with $\mathrm{L} / \mathrm{iD}$ above 20 , often used at high temperature for calcination of limestone, petroleum coke, or production of cement. Other applications include: regeneration of spent catalyst, hazardous waste reclamation, defluorination and reduction of uranyl difluoride and so on. Kilns are usually equipped with internal fixtures such as lifters, baffles, constrictions or exit dam.

The complex hydrodynamic behavior of the granular materials within rotary kilns has led to extensive research over the years. Among the first to investigate this subject, Sullivan et al. [1] and others later [2-5], focused on the time of passage of solid particles. This has been the simplest approach to get some understanding of the solids transport. However, this method can be inaccurate with regard to the distribution of the times that solid particles will undergo inside the kiln. Variations of times which may be observed are therefore represented by the residence time distribution (RTD) at steady state flow. Because the knowledge and a good characterization of the RTD are necessary for the design, improvement and scale-up of manufacturing process, there have been some recent published works on the experimental and theoretical analysis of the solids transport using the RTD notion. Most of these publications report on the influence of operating parameters (rotational speed, kiln slope, mass flow rate or exit dam height) [6-20] and others on the influence of the bulk or tracer materials properties [11], or segregation phenomena [14, 19, 21]. Fewer are those analyzing the effect of presence of lifters, their number or shape $[10,14,17]$. However, some authors have focused on the study of lifters hold-up and discharging rate [5, 22-31].

RTD experiments usually involve tracer detection techniques. The stimulus response test is a common method used for measurements of the RTD $[32,33]$. In this test, the injection of either a step change or a pulse of tracer is performed at the inlet end. The tracer materials must share similar physical properties with the bulk materials. The tracer detection can be either inline by means of inline probes, therefore requiring fast sample acquisition, or offline, in which case the detection is performed either optically (fluorescence analysis, spectroscopy, near infrared and ultraviolet), by measuring the conductivity, or by counting and weighing.

Several models have been used and developed to describe the experimental RTD of solid particles through the kiln. The most popular used is the axial dispersion model. In addition to the mean residence time, this model provides a dispersion parameter, able to characterize the material transport behavior. A similar model is the tank in series model. These two models are usually called one-parameter models, as opposed to the multi-parameter models. Among the multi-parameter models are: the modified Cholette-Cloutier model used by Duchesne et al. [34], and the models developed by Mu and Perlmutter [35], Sheehan et al. [36], Dinesh V and Sai [37], Sheehan et al. [38], Britton et al. [39]. Generally these one-parameter or multi-parameter models can give quantitative predictions about the materials transport behavior, thus giving an insight on the deviation from the two ideal extremes. The flow in rotary kilns are likely closed to that of plug flow reactors.

This paper is concerned with the effects of kiln rotational speed, kiln slope, mass flow rate, exit dam height, lifters shape and bulk materials properties on:

- the RTD of solid particles, determined from experimental stimulus response test; 


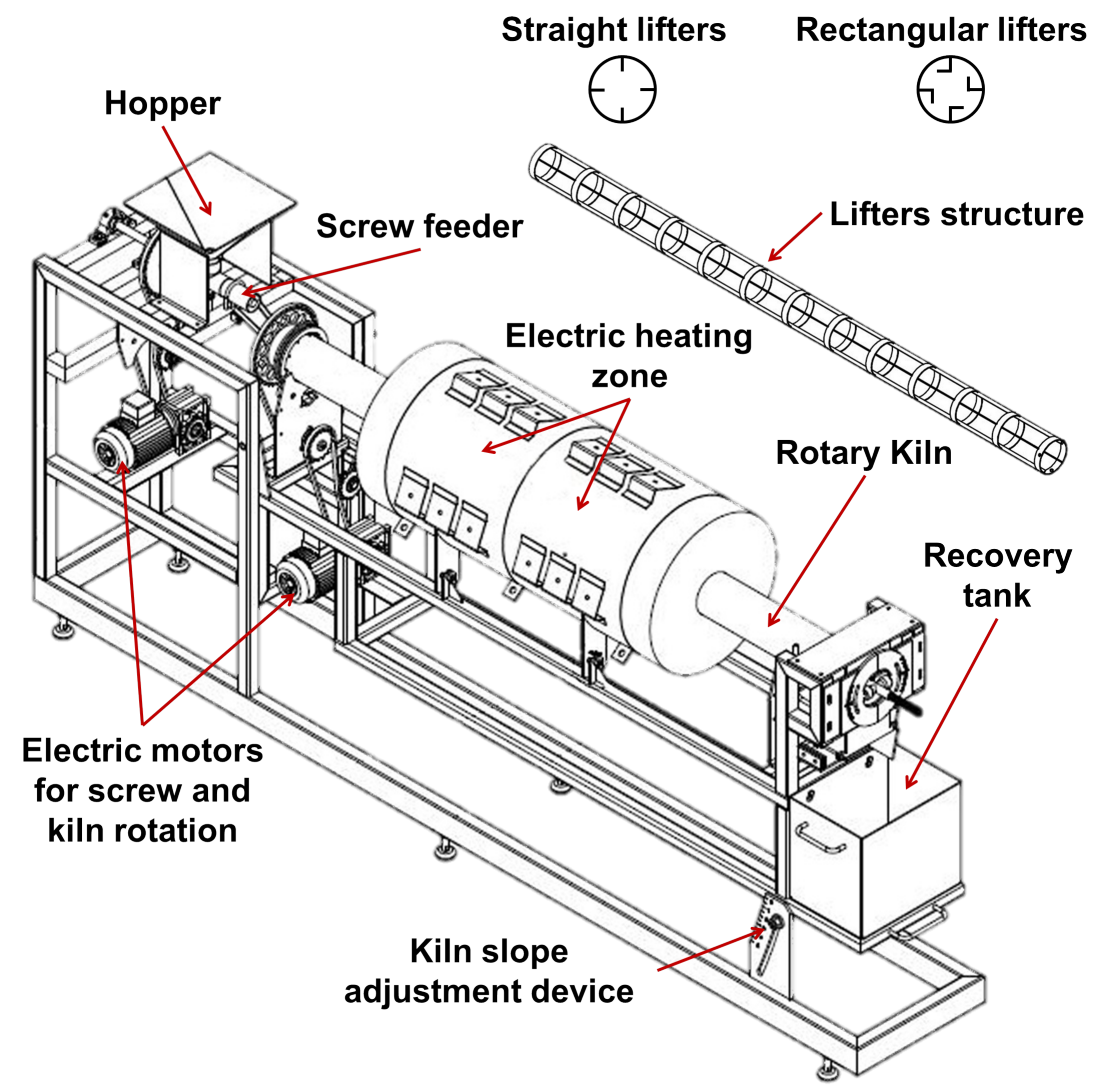

Fig. 1: Layout of the experimental apparatus, including the structure and shapes of lifters.

- the Peclet number as well as the corresponding axial dispersion coefficient, which characterizes the materials transport and mixing within the system.

The experimental results are interpreted in light of the axial dispersion model for the RTD, and the validity of the model is assessed on the full set of data. After checking the experiments reproducibility, the RTDs and the corresponding variances, Peclet numbers and axial dispersion coefficients are analyzed in terms of the operating parameters. Eventually a correlation to predict the axial dispersion coefficient is given for kiln equipped with lifters and the calculated coefficients are compared with the experimental results. Predictions of other published correlations are also compared to the experimental results.

\section{Materials and methods}

\subsection{Apparatus and materials}

A pilot scale rotary kiln was used to carry out the investigation of solid particles motion. The layout of the experimental system is shown in Fig.1. The main parts of this set up are the feeding system and the rotating kiln followed by a recovery zone. 
Table 1: Geometrical characteristics of the rotary kiln

\begin{tabular}{|c|c|c|}
\hline Subsets & Parameters & $\begin{array}{c}\text { Order of } \\
\text { magnitude }\end{array}$ \\
\hline \hline \multirow{3}{*}{$\begin{array}{c}\text { Rotary } \\
\text { Kiln }\end{array}$} & iD [m] & 0.1013 \\
\cline { 2 - 3 } & L [m] & 1.95 \\
\cline { 2 - 3 } & $\begin{array}{c}\text { Exit dam } \\
\text { height [mm] }\end{array}$ & $0-33.5$ \\
\cline { 2 - 3 } & Lifters shape & None, SL, RL \\
\hline \hline \multirow{2}{*}{$\begin{array}{c}\text { Operating } \\
\text { conditions }\end{array}$} & $\mathrm{N} \mathrm{[rpm]}$ & $2-12$ \\
\cline { 2 - 3 } & ${\dot{\mathrm{M}}\left[{ }^{\circ}\right]}^{\left.\mathrm{kg} \cdot \mathrm{h}^{-1}\right]}$ & $2-5$ \\
\cline { 2 - 3 } &
\end{tabular}

The feeding system is mainly a combination of a hopper and a feed screw. The hopper acts as a storage where the bulk materials are manually poured. The solid particles flow by gravity from the bottom of the hopper through a feed screw. This later delivers the solid particles to a feed chute ending up at the kiln inlet end. There is no possible access to recover the solids at the kiln inlet end. Therefore the feed rate is controlled at the kiln outlet and regulated by adjusting the rotational frequency of a $180 \mathrm{~W}$ DC motor, which drives the screw feeder by means of a belt drive. Thus the feed rate measurements were achieved when steady-state flow conditions were established.

The rotary kiln is a tube made of an Incoloy alloy 800 and measures $1.95 \mathrm{~m}$ in length and $0.101 \mathrm{~m}$ in (internal) diameter. For the purpose of the residence time distribution study, the smooth inner wall can be equipped with a network or a structure of lifters when necessary. Each structure is fitted with 4 identical lifters equally distributed in the periphery. Two shapes of lifters were used: straight one-section lifters of $10 \mathrm{~mm}$ refer to as straight lifters (SL) and two-section lifters of $10 \mathrm{~mm}$ each, with a right angle cross section refer to as rectangular lifters (RL) as shown in Fig.1. The kiln tube is supported on 4 rollers, and is driven through chain and sprocket and a variable speed $180 \mathrm{~W}$ DC motor. This setting allows kiln operation at speeds ranging from 2 to $12 \mathrm{rpm}$. At the discharged end, constriction dams of different height can be installed in order to restrict the flow of solids, so that the filling degree within the kiln varies irrespectively of the solids flow rate or kiln rotational speed. The kiln slope is measured using an electronic level. The slope can be modified by means of an hydraulic jack with manual pump and an adjustment device. So, the kiln unit can be tilted to an angle of $5^{\circ}$. Table 1 summarizes the geometrical and operational characteristics of the kiln in this study.

In order to investigate the motion of solid particles of different properties within the kiln, two granular solids were used as bulk materials: (1) dry nodular sand characterized by a $1422 \mathrm{~kg} \cdot \mathrm{m}^{-3}$ bulk density, a mean particle size of $0.55 \mathrm{~mm}$ and an angle of repose of $39^{\circ}$; (2) broken rice characterized by a $889 \mathrm{~kg} \cdot \mathrm{m}^{-3}$ bulk density, a mean particle size of $3.8 \mathrm{~mm}$ in length and $1.9 \mathrm{~mm}$ in diameter, and an angle of repose of $36^{\circ}$. Table 2 shows some of the most important properties of the materials used. The bulk density was determined by measuring the weight of materials which occupied a volume of 100 $\mathrm{mL}$ in a graduated cylinder. In order to determine the tapped density this latter was compacted by "hand tapping" the measuring cylinder about a minute, approximately 200 
Table 2: Physical properties of materials

\begin{tabular}{|c|c|c|c|c|c|}
\hline Product & Shape & $\begin{array}{c}\rho_{\text {bulk }} \\
{\left[\mathrm{kg} \cdot \mathrm{m}^{-3}\right]}\end{array}$ & $\begin{array}{c}\rho_{\text {tapped }} \\
{\left[\mathrm{kg} \cdot \mathrm{m}^{-3}\right]}\end{array}$ & $\begin{array}{c}d_{p} \\
{[\mathrm{~mm}]}\end{array}$ & $\begin{array}{c}\theta \\
{\left[{ }^{\circ}\right]}\end{array}$ \\
\hline \hline Sand & Nodular & 1422 & 1543 & 0.55 & 39 \\
\hline $\mathrm{NaCl}$ & Nodular & 1087 & 1184 & 0.6 & 35.4 \\
\hline Broken rice & Cylindrical & 889 & 934 & $3.8 \times 1.9$ & 36 \\
\hline
\end{tabular}

times (on average) from 10 to $20 \mathrm{~mm}$ height and the new volume was measured. However the raising and lowering of the cylinder were done without reference to the height and arbitrary acceleration in both directions (upward and downward). The solids angle of repose were determined by means of the fixed cone method similarly to Thammavong et al. [40].

\subsection{Experimental technique}

The experiments performed in this study were conducted at ambient temperature with a procedure mostly similar to Abouzeid et al. [7]. The RTDs were determined by stimulus response tests using dyed sand and sodium chloride as tracers for sand bulk flow, and dyed rice as tracer for rice bulk flow. Depending on the bulk materials, the procedure may differ in few points as follows:

Step 1: Before starting a run, the variable parameters $(\mathrm{N}, \mathrm{S}, \dot{\mathrm{M}})$ are set to the desired values, the suitable lifters and exit dam are installed for the experiment. The rotary kiln, operating at atmospheric pressure, is then started and the feed hopper regularly fulfilled with the operating solids to keep it topped up till the end of the run.

Step 2: The system is run until it reaches steady-state conditions, usually after 4 hours. The steady state is assumed to be reached when at least three consecutive measurements of the flow rate at the kiln outlet are almost equal within a margin of $\pm 0.05 \mathrm{~kg} . \mathrm{h}^{-1}$. The flow rate was measured by weighing the materials collected at the kiln outlet during a period of $15 \mathrm{~min}$.

Step 3: In the case of a bulk of sand, a preliminary test was performed with dyed sand tracer to determine approximately the starting and stopping time of the sampling. Then a known amount of $\mathrm{NaCl}$ tracer was injected in the feed chute at an arbitrary zero time. Tracer injections lasted about 2 sec, which have been assumed short enough (with regard to measured residence times) to approximate an impulse input. Samples of 5 $\mathrm{g}$ were collected at the kiln outlet at constant time intervals of $30 \mathrm{sec}$. In the case of a bulk of broken rice, a known amount of dyed broken rice was injected in the feed chute at an arbitrary zero time. Samples were continuously collected at the kiln exit end with a sampling time of $30 \mathrm{sec}$ until all tracer materials had discharged.

Step 4: The rotary kiln rotation was stopped and the screw feeder disabled at the same time. Only the kiln rotation was started again and the solids could be discharged. The collected solids which constitute the kiln hold-up were weighted.

Step 5: Eventually, in the case of a bulk of sand, each collected sample was weighted, then mixed with $20 \mathrm{~mL}$ of distilled water in order to dissolve the $\mathrm{NaCl}$ particles if present. The sample conductivity, which is proportional to the concentration of diluted $\mathrm{NaCl}$ tracer, was then measured. Whereas in the case of a bulk of broken rice, tracer 


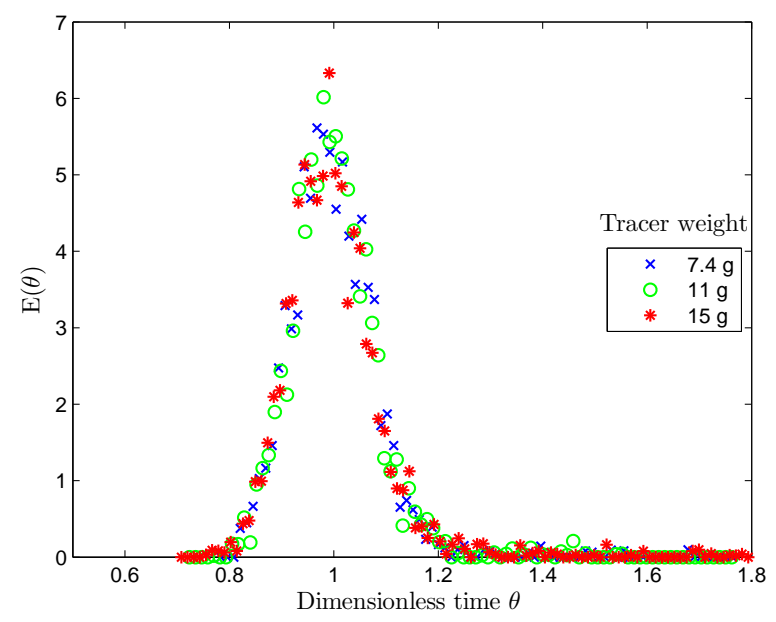

Fig. 2: Effect of the amount of tracer (dyed broken rice) upon the dimensionless RTD in a bulk of broken rice. Operating conditions: $3 \mathrm{rpm}$ rotation speed, $2^{\circ}$ slope, $2.5 \mathrm{~kg} . \mathrm{h}^{-1} \mathrm{MFR}, 23.5 \mathrm{~mm}$ exit dam height with rectangular lifters.

concentration in each sample was determined by weighting on one hand the sample and, on the other hand the dyed tracer contained in the sample.

The choice of tracer is important. Indeed, selected tracers were expected to share similar properties with the bulk materials, thus introducing as few disturbances as possible on the bulk flow. For the bigger particles size (broken rice) dyed particles were chosen, otherwise except for the color the tracer materials were identical to the bulk. And for the small particle size (sand), the tracers were sodium chloride particles of same size rather than dyed particles due to time consuming samples analysis. No less importantly, the amount of tracer to be injected should be well defined to provide the desired accuracy for analysis [7]. Therefore experiments were conducted with different amount of dyed broken rice and resulting dimensionless residence time distribution were analyzed to assist decision-making. As shown in Fig.2 for amount of tracer varying from $7.4 \mathrm{~g}$ to $15 \mathrm{~g}$ the dimensionless RTD was not significantly affected, making easier the decision. Since the sampling analysis lasted longer with increasing amount of tracer, $7.4 \mathrm{~g}$ of tracer were used in experiments involving broken rice. To keep approximately a similar volume of tracer in all experiments, in the case of sand 10-12 g of tracer were needed. For a more accurate data $12 \mathrm{~g}$ of tracer were used in experiments involving sand.

\section{Data processing}

\section{Data evaluation}

When performing a stimulus test, the fraction of tracer that remains in the system at any time is described by the distribution function $\mathrm{E}(\mathrm{t})$ as follows :

$$
\mathrm{E}(\mathrm{t})=\frac{\mathrm{C}(\mathrm{t})}{\int_{0}^{\infty} \mathrm{C}(\mathrm{t}) d t}
$$


where $\mathrm{C}(\mathrm{t})$ represents the tracer concentration at the kiln exit end and the time integral of $\mathrm{C}(\mathrm{t})$ represents the total tracer concentration. In this study, for each sample the tracer concentration (or conductivity) was yielded, so that from the discrete sample, and associated sampling time $\Delta t_{i}, \mathrm{i}=\left\{1,2,3, \ldots, N_{s}\right\}$, the RTD curve or E-curve of each experiment can be determined as follows [41]:

$$
E\left(t_{i}\right) \cong \frac{\mathrm{C}\left(\mathrm{t}_{\mathrm{i}}\right)}{\sum_{i}^{N_{S}} \mathrm{C}\left(\mathrm{t}_{\mathrm{i}}\right) \Delta t_{i}}
$$

The Interpretation of the RTD curves is based on moment analysis which provides various aspect of the flow in the unit. The first moment of the RTD function gives the mean residence time (MRT) $\bar{t}$ which is defined by [41]:

$$
\bar{t}=\frac{\int_{0}^{\infty} t \mathrm{C}(\mathrm{t}) d t}{\int_{0}^{\infty} \mathrm{C}(\mathrm{t}) d t} \cong \frac{\sum_{i}^{N_{S}} t_{i} \mathrm{C}\left(\mathrm{t}_{\mathrm{i}}\right) \Delta t_{i}}{\sum_{i}^{N_{S}} \mathrm{C}\left(\mathrm{t}_{\mathrm{i}}\right) \Delta t_{i}}
$$

The second moment of the RTD function, $\sigma^{2}$, gives the variance of residence times (VRT) about the MRT. It indicates the width or scatter of the distribution: the greater the value of this moment, the greater the distribution spread. This moment is defined as follows [41]:

$$
\sigma^{2}=\frac{\int_{0}^{\infty}(t-\bar{t})^{2} \mathrm{C}(\mathrm{t}) d t}{\int_{0}^{\infty} \mathrm{C}(\mathrm{t}) d t} \cong \frac{\sum_{i}^{N_{S}} t_{i}{ }^{2} \mathrm{C}\left(\mathrm{t}_{\mathrm{i}}\right) \Delta t_{i}}{\sum_{i}^{N_{S}} \mathrm{C}\left(\mathrm{t}_{\mathrm{i}}\right) \Delta t_{i}}-\bar{t}^{2}
$$

Since the sampling time was constant and equal in all experiments, the sampling intervals in Eqs.3 and Eqs.4 can be simplified. The presented E(t) function and VRT can also be expressed in dimensionless form:

$$
\begin{aligned}
\theta & =\frac{t}{\bar{t}} \\
\mathrm{E}(\theta) & =\bar{t} \mathrm{E}(t) \\
\sigma_{\theta}^{2} & =\frac{\sigma^{2}}{\bar{t}^{2}}
\end{aligned}
$$

respectively the dimensionless time, mean residence time and variance of residence time.

\section{Axial dispersion model}

The axial dispersion model is used to represent the RTDs. Originally used by Danckwerts [42], this model considers the axial motion of fluid element as two components [33]: a convective component arising from the bulk motion of the fluid and a diffusive component arising from the random motion of solids in response to the decay of turbulent eddies. This is represented by the following one-dimensional Fokker-Planck equation, which describes the evolution of particle distribution in continuous systems [43, 44]: 


$$
\begin{aligned}
\frac{\partial C}{\partial \theta} & =\frac{1}{P e} \frac{\partial^{2} C}{\partial z^{2}}-\frac{\partial C}{\partial z} \\
\frac{D}{u L} & =\frac{1}{P e} \\
\theta & =\frac{t}{\bar{t}}=\frac{u t}{L}
\end{aligned}
$$

where $\mathrm{D}$ is the axial dispersion coefficient in $\mathrm{m}^{2} \cdot \mathrm{s}^{-1}$, Pe is the dimensionless Peclet number, $\mathrm{z}$ is dimensionless and defined as the ratio of the axial position to the kiln length $\mathrm{L}, t$ and $\bar{t}$ are respectively the time and the MRT in $\mathrm{s}, u$ is the velocity in $\mathrm{m} . \mathrm{s}^{-1}$. This continuum model has been applied in rotary kilns $[7,10,12,16,20,44,45]$ to describe the transport of granular solids providing that some assumptions are satisfied. Among the most important $[7,16,36]$ :

(i) Steady-state conditions must be achieved and maintained over the tracer stimulus test.

(ii) A delta-dirac tracer pulse insuring that tracer concentration is only function of time and axial position.

(iii) Constant axial convective velocity and axial dispersion coefficient of tracer for stable operating conditions

Analytical solutions for the RTD were published by several authors $[7,8,41,46]$ for the different type of boundary conditions. In this study the flow of materials was undisturbed at the inlet and outlet, so that the open-open boundary condition is considered for the system.

The analytical solution for Eq.8, acknowledging the open-open boundary condition, published by Levenspiel [41] is given in a dimensionless form as follows:

$$
E(\theta)=\frac{1}{2} \sqrt{\frac{P e}{\pi \theta}} \exp \left\{-\frac{P e(1-\theta)^{2}}{4 \theta}\right\}
$$

The mean and variance of this distribution are defined as:

$$
\begin{gathered}
\bar{t}_{o o}=1+\frac{2}{P e} \\
\sigma_{\theta, o o}^{2}=\frac{2}{P e}+\frac{8}{P e^{2}}
\end{gathered}
$$

There are two main methods to evaluate the Peclet number: the simplest one is to match the measured variance (Eq.4) to theory (Eq.13), the other one imply to fit the experimental E-curve using the dispersion model (Eq.11). These two methods are considered in the coming section to evaluate the Peclet numbers and resulting axial dispersion coefficients for varying experimental conditions. 
Table 3: Reproducibility of experiments

\begin{tabular}{|c|c|c|c|c|c|}
\hline $\begin{array}{c}\text { Materials } \\
\text { - Lifters }\end{array}$ & Operating conditions & $\begin{array}{c}\bar{t} \\
{[\mathrm{~min}]}\end{array}$ & $\begin{array}{c}\mathrm{Cv} \\
{[\%]}\end{array}$ & $\begin{array}{c}\sigma^{2} \\
{\left[\mathrm{~min}^{2}\right]}\end{array}$ & $\begin{array}{c}\mathrm{Cv} \\
{[\%]}\end{array}$ \\
\hline \hline Sand & $3 \mathrm{rpm}, 2.1^{\circ}, 2.5$ & 43.39 & & 6.91 & \\
& $\mathrm{~kg} \cdot \mathrm{h}^{-1} \mathrm{MFR}, 23.5$ & 43.64 & 0.76 & 6.72 & 11.2 \\
$\mathrm{SL}$ & $\mathrm{mm}$ exit dam height & 42.99 & & 8.22 & \\
\hline Broken & $3 \mathrm{rpm}, 2.5^{\circ}, 2.5$ & 31.77 & & 8.57 & \\
rice & $\mathrm{kg} \cdot \mathrm{h}^{-1} \mathrm{MFR}, 23.5$ & & 0.67 & & 5.9 \\
$\mathrm{RL}$ & $\mathrm{mm}$ exit dam height & 31.47 & & 7.88 & \\
\hline Broken & $10 \mathrm{rpm}, 2^{\circ}, 2.5$ & 13.38 & & 2.98 & \\
rice & $\mathrm{kg} \cdot \mathrm{h}^{-1} \mathrm{MFR}, 23.5$ & 13.14 & 2.1 & 3.37 & 19.2 \\
$\mathrm{NL}$ & $\mathrm{mm}$ exit dam height & 12.83 & & 2.28 & \\
\hline
\end{tabular}

\section{Results and discussion}

In this study, benchmark values of a range of operating conditions were defined, so that every operating parameter was kept constant except the one being studied. Whatever the materials being processed, in presence or not of lifters (SL or RL), the benchmark values were a rotational speed of $3 \mathrm{rpm}$, a kiln slope of $2^{\circ}$, a mass flow rate of $2.5 \mathrm{~kg} . \mathrm{h}^{-1}( \pm 0.05$ $\mathrm{kg} \cdot \mathrm{h}^{-1}$ ) and a $23.5 \mathrm{~mm}$ exit dam height. The rotary kiln was either over-loaded or designloaded during the experiments. Hence a set of 69 experiments was performed. The main purposes of these latter being to investigate: (1) the residence time entire distribution, (2) the mean residence time of the distribution which is discussed elsewhere separately [47], (3) the variance of residence time, (4) the validity of the axial dispersion model, (5) the Peclet number and axial dispersion coefficient.

In order to test the reproducibility, an additional 20 experiments were performed. Some of these experiments are reported in Table 3. Fig.4 displays some repeated experiments with a bulk of broken rice while using straight, rectangular, or no lifters at $10 \mathrm{rpm}$ with other parameters kept at the benchmark values. From this, it is clear that the reproducibility is good, but greater variations were observed at high rotational speed, thereby supporting the chosen benchmark value. These variations derived from a variety of sources [7] ranging from the feeding system to the sampling analysis and including the tracer injection and discharge sampling procedures. Results from the overall replicated experiments showed that the coefficients of variation of the mean residence time and the variance of RTD are on average $1.2 \%$ and $16.2 \%$, respectively. In light of this, results from the experimental campaign were considered as sufficiently reliable for the analysis of the influence of operating parameters upon the materials transport in a rotary kiln equipped with lifters.

\subsection{Axial dispersion model}

The axial dispersion model presented above was used to represent the time dependent E-curves. Therefore, to determine the RTD equation, Eq.11 is rewritten in dimensional form using Eq.5 and Eq.6 as follows: 

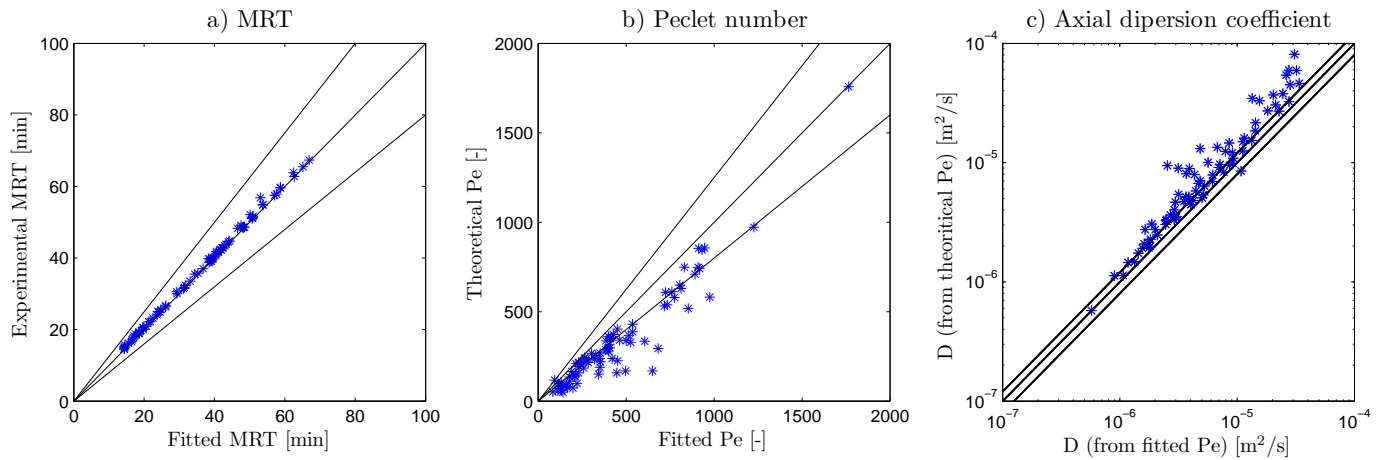

Fig. 3: Comparison of experimental/theoretical and fitted values of the axial dispersion model parameters, i.e MRT, Pe, and resulting D. Solids lines are $\pm 20 \%$ margins.

$$
E(t)=\frac{1}{2} \sqrt{\frac{P e}{\pi \bar{t} t}} \exp \left\{-\frac{P e(\bar{t}-t)^{2}}{4 \bar{t} t}\right\}
$$

While the dimensionless form of the model needs only a unique parameter namely the Peclet number, in its dimensional form there is a second parameter to determine: the mean residence time of the distribution. As explained before there are two methodologies. Both of them are considered:

Case 1: The MRT is obtained from experimental data using Eq.3. The Peclet number is obtained from the theoretical expression described in Eq.13 using the dimensionless VRT obtained from experimental data using Eq.7.

Case 2: The parameters are determined to minimize the mean sum of square error between the experimentally determined RTD values using Eq.2 and the predicted values from Eq.14. Parameters for the best fitted curve were calculated through a MatLab script using the curve fitting tool function.

Parameters deriving from the above methodologies are used in Fig.7, which shows the influence of operating parameters on the RTD of broken rice, to investigate the validity of the axial dispersion model. The simulated curves using the case 1 parameters, referred to as theoretical parameters, are dashed lines. The simulated curves using the case 2 parameters, referred to as fitted parameters, are solid lines. It appears clearly that both sets of parameters give good agreement with experimental data; that was the case for experiments of the whole campaign. However, as one would have expected, fitted parameters lead to better results than theoretical parameters. Although theoretical parameters are simple to obtain, they are not necessarily the best choice. A comparison of theoretical and fitted parameters is given in Fig.3. Experimental and fitted MRT are perfectly correlated (see Fig.3a), whereas theoretical and fitted Peclet numbers exhibit some discrepancy. Consequently, it is recognized that the theoretical Peclet numbers reported in this study are likely underestimating the actual Peclet numbers as suggested in Fig.3b. However, with regard to the validity of the chosen model, one may keep in mind that some irregularities can occur at inlet and outlet ends of the kiln, reducing the model accuracy. 


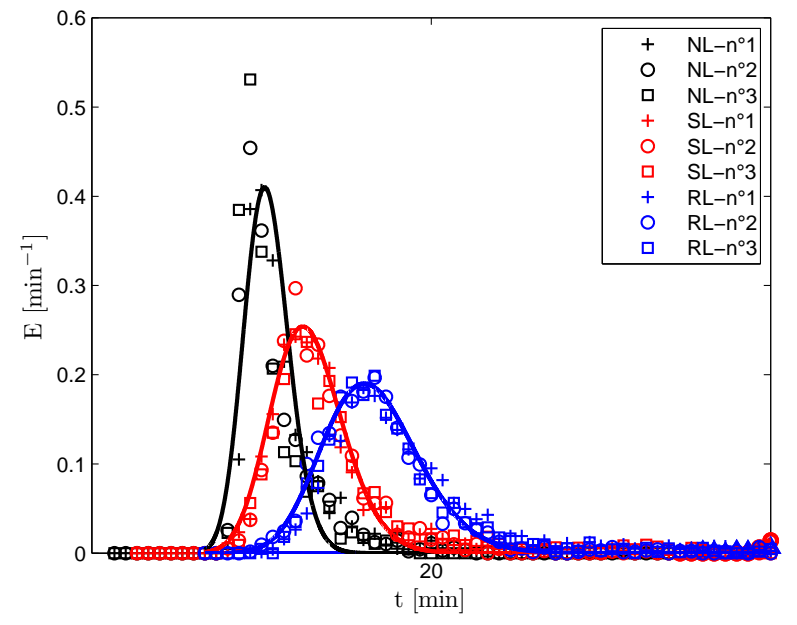

Fig. 4: Effect of presence and shape of lifters on the RTD for the flow of broken rice. Operating conditions: $10 \mathrm{rpm}$ rotation speed, $2^{\circ}$ slope, $2.5 \mathrm{~kg} \cdot \mathrm{h}^{-1} \mathrm{MFR}, 23.5 \mathrm{~mm}$ exit dam height. In each case (NL, SL and RL), the experiment was repeated three times. Solid lines are the axial dispersion model of the $n^{\circ} 1$ replicated run with fitted parameters

The Peclet number expressed the ratio of the axial convection forces to the dispersion forces as given in Eq.9. Subsequently it is possible to obtain the axial dispersion coefficient from theoretical and fitted Peclet number. The calculated axial dispersion numbers were found in the range of $10^{-7}$ to $10^{-4} \mathrm{~m}^{2} \cdot \mathrm{s}^{-1}$ highlighted by Sherritt et al. [44] for kiln diameters ranging from 0.076 to $0.144 \mathrm{~m}$ not always equipped with lifters and/or exit dam (from published data). Axial dispersion coefficients calculated from theoretical Peclet numbers were found in general higher than those obtained from fitted Peclet numbers (see Fig.3c). From now on, only results obtained from the fitted parameters are considered.

\subsection{Influence of operating variables and nature of materials on the RTD}

There have been several research works investigating the same scope of this study. However very few experiments on residence time using materials of different physical properties, were performed in rotary kiln equipped with different shape of lifters to study transport of particulate solids. Earlier studies [10, 14, 15] differ from the present investigation with regard to the design of apparatus, the operating conditions, the experimental procedures, or the materials used.

\section{Effect of lifters profile}

Fig.4 presents RTDs obtained while processing broken rice, with the kiln equipped with straight, rectangular and no lifters. The three curves are overlapping, but still a distinction can be found with regards to values of the MRT and the VRT, which are adequate for the analysis. Notably, as previously stated, the VRT gives an indication about the spread of the distribution.

The following orders apply in these experiments: 


$$
\bar{t}_{N L}<\bar{t}_{S L}<\bar{t}_{R L} \text { and } \sigma_{N L}^{2}<\sigma_{S L}^{2}<\sigma_{R L}^{2} .
$$

The experiments performed in this study, for a given type of materials when all operating parameters but the shape of the lifters are kept constant, showed the exact same trend here observed for MRT and VRT of the distribution. Regarding the MRT: RL experiments always have higher MRT than those of SL experiments or NL experiments. This may first be explained by the maximum hold-up of loading lifters. As stated before, the kiln was either over-loaded or design-loaded during the experiments, so that lifters could be filled to their maximum capacity. Let's calculate the volume of solids in a loading lifter for both geometries at horizontal position following Debacq et al. [48] calculations. Assuming the slope drawn by solids in the lifters is equal to the static angle of repose, $V_{S L}=75.8 \mathrm{~cm}^{3}$ and $V_{R L}=242 \mathrm{~cm}^{3}$, if the bulk materials are sand particles. One may assume that while being regularly kept inside lifters, solid particles are somehow delayed until being cascaded from the lifters with respect to solids inside the kilning bed (which are not taking extra routes or trajectories). Hence the axial transport of particles occurs mainly in the kilning bed. This may be the simple reason why in the presence of lifters, the residence times of solids are increased. But this must not be a sufficient analysis to understand the effect of the lifters' shape or profile. For that, it is necessary to study the discharge rate of lifters. Since there have been recent studies reporting on that field $[30,48]$, such a study was not necessary, but still it was possible to observe the angular position $\gamma_{f}$ of a lifter at the end of discharge (with respect to the horizontal). It was found that $\gamma_{f_{S L}}<\gamma_{f_{R L}} \cdot \gamma_{f_{S L}}$ was within the range of $20^{\circ}$ to $40^{\circ}$ whereas $\gamma_{f_{R L}}$ was within the range of $120^{\circ}$ and $140^{\circ}$. This implies that on average the SL were totally discharged before RL, every other operating parameter remaining constant. Thus, solid particles were less delayed when using straight lifters, explaining why residence times were higher when the kiln was equipped with rectangular lifters. It was observed that SL were already empty above $40^{\circ}$, while RL were still cascading solids. It is therefore recognized that RL produce more effect of mixing than SL, because they discharge through almost the whole kiln cross section with a relatively sustained rate. This explains why results showed $\sigma_{S L}^{2}<\sigma_{R L}^{2}$ as displayed in Fig.6.

\section{Effect of materials of differing physical properties}

The two materials used in the study, namely sand and rice, are very different as indicated by their properties given in Table 2. Fig.5 presents examples of distribution curves obtained while processing these materials in similar operating conditions.

A first remark to be made is that largest solid particles (broken rice) always have smaller residence times compared to the smaller solids particles (sand). In the presence of lifters, rolling motions were observed in the kilning bed. Assuming that lifters, in particular straight lifters, do not affect the flow regimes but only reduce the area of the central core in the bed at the bottom of the kiln as suggested by Grajales et al. [49] analysis of Chaudhuri et al. [50] experiments and simulations, the main physical property responsible for the differing residence times is likely to be the angle of repose. That is because in this type of motion, as explained by Mellmann [51], the larger part of the bed is transported as a solid body upwards with the rotational speed of the wall to the surface layer where particulates roll on themselves from the apex, between or over the lifters. As mentioned by Friedman and Marshall [52] the kilning effect decreases with increasing angle of repose of the materials. Thus, the higher the angle of repose, the 


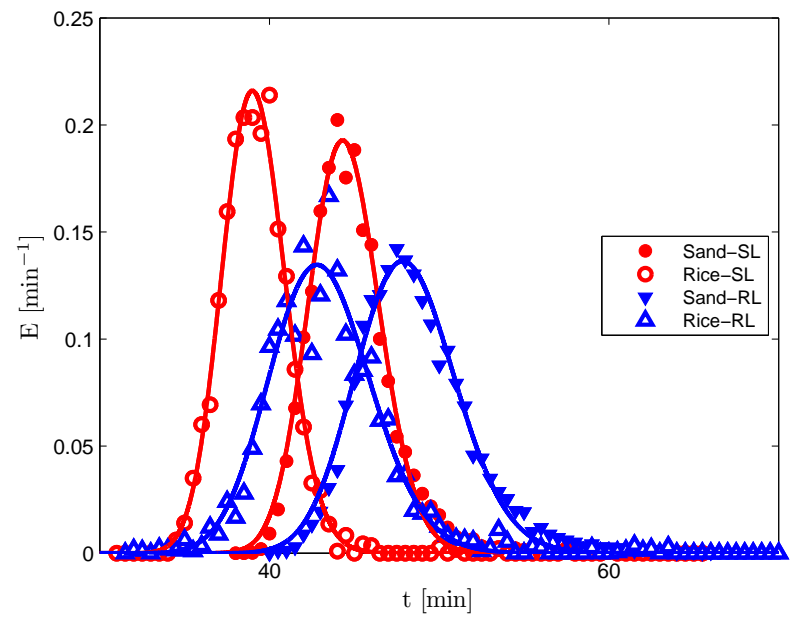

Fig. 5: Effect of the bulk materials characteristics on the RTD. Operating conditions for both SL and RL: $3 \mathrm{rpm}$ rotation speed, $2^{\circ}$ slope, $2.5 \mathrm{~kg} \cdot \mathrm{h}^{-1} \mathrm{MFR}, 23.5 \mathrm{~mm}$ exit dam height. Solid lines are the axial dispersion model with fitted parameters.

higher the time for solid particles to roll down at the surface layer. This latter, combined with effects of gravity, can explain why the rice residence times are shorter compared to those of the sand particles.

Secondly the RTD curves displayed in general nearly the same width: over the whole experimental campaign the VRT obtained were generally of the same order of magnitude for both materials at equivalent operating conditions (see Fig.6) except when varying the kiln slope and the feed rate. In the latter cases significant deviations were observed.

Effect of operating parameters: rotational speed, kiln slope, flow rate and exit dam height

Effects of profile of the lifters and nature of the bulk materials have been previously discussed, therefore Fig.7 shows the influence of the remaining operating parameters in this study in the case of a bulk of broken rice when the kiln is equipped with rectangular lifters.

Rotational speed. As shown in Fig.7a, an increase of the kiln rotational speed from 2 to $12 \mathrm{rpm}$ has caused a remarkable shift of the RTD towards lower and lower residence times, while the shape (width and height of the peak) of these RTD curves remains approximately unchanged. Within this range of rotational speed, had the kiln not been equipped with lifters, the motion of the particles in the rotary kiln could be described as rolling with regards to Mellmann [51] criteria. These results agreed with Abouzeid et al. [7] experiments ranging from rolling to cataracting bed in a small cylinder, but industrial applications are usually within the rolling motion. For a given type of materials and shape of lifters, the VRT remained approximately steady (see Fig.6a) as implied by the similar width displayed by the corresponding RTD curves.

Kiln slope. Even though that some industrial applications have used horizontal rotary kiln $[9,45,53]$, most kilns are designed to operate in an inclined position. Therefore our 

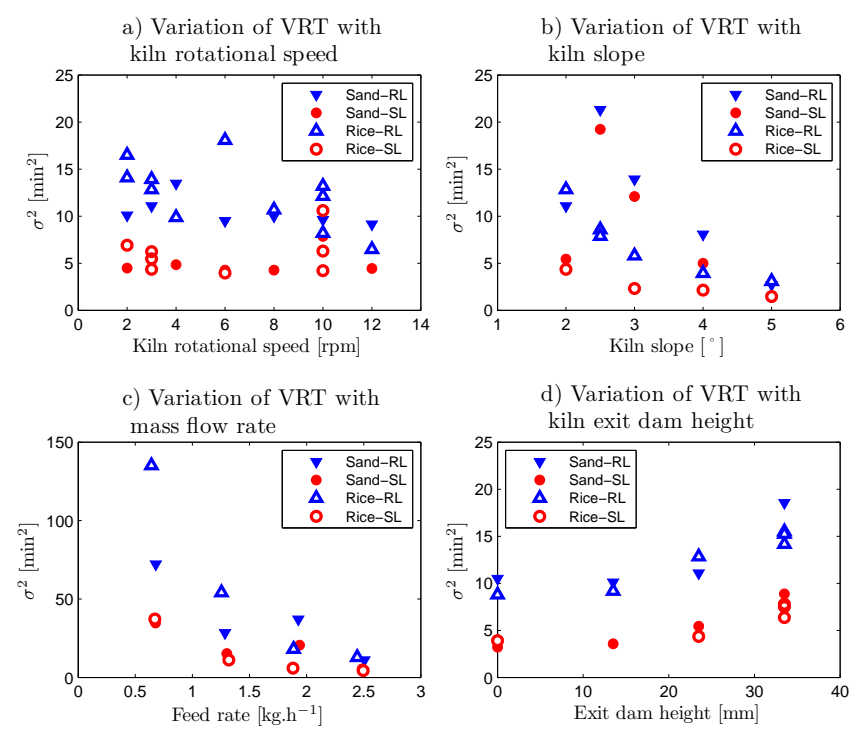

Fig. 6: Influence of operating parameters (N, S, $\dot{M}$ and exit dam height) on the VRT for the flow of sand and broken rice, when the kiln is equipped with either straight or rectangular lifters.

investigations extended from 2 to 5 degrees slope. Fig.7b shows that RTD curves shift left towards lower residence time regions, while demonstrating gradual changes in their shape. These latter changes may be explained by the gradual decrease observed on the VRT from $2.5^{\circ}$ kiln slope. Results also show in Fig.6b that sand VRT are slightly higher to those of broken rice.

Mass flow rate. It may be seen from Fig.7c, that RTD curves are overlapping. When the solid flow rate decreases from 2.5 to $0.68 \mathrm{~kg} \cdot \mathrm{h}^{-1}$, RTD curves gradually spread and flatten, while slowly moving forward so that the residence time of the particles increases. The VRT were found to diminish with increasing feed rate (see Fig.6c). By qualitative comparison, these results agreed well with those published previously $[7,9]$.

Exit dam height. Eventually it was found that RTD curves shift on the right side (i.e toward region of higher residence time) and become flatter and broader as the exit dam height increases from 0 to $33.5 \mathrm{~mm}$. RTD curves of experiments with a $13.5 \mathrm{~mm}$ exit dam height or nothing installed at the kiln outlet, were completely overlapping, in fact nearly the same. This is shown in Fig.7d. Thus, results suggest that dams covering less than $45 \%$ of the area at the kiln outlet will not have a significant impact on the residence time of solid particles. However, that conclusion should likely apply to kilns having similar $\mathrm{L} / \mathrm{iD}$ ratios to the one used in this study. The VRT exhibits a plateau before slowly increasing with the exit dam height as shown in Fig.6d.

\subsection{Influence of operating variables and nature of materials on the Pe and D}

The Peclet numbers obtained in this study are very high usually larger than 100 . This is generally common when the flow behavior of the stream in a unit tends toward plug 
a) Influence of kiln rotational speed - RL and broken rice

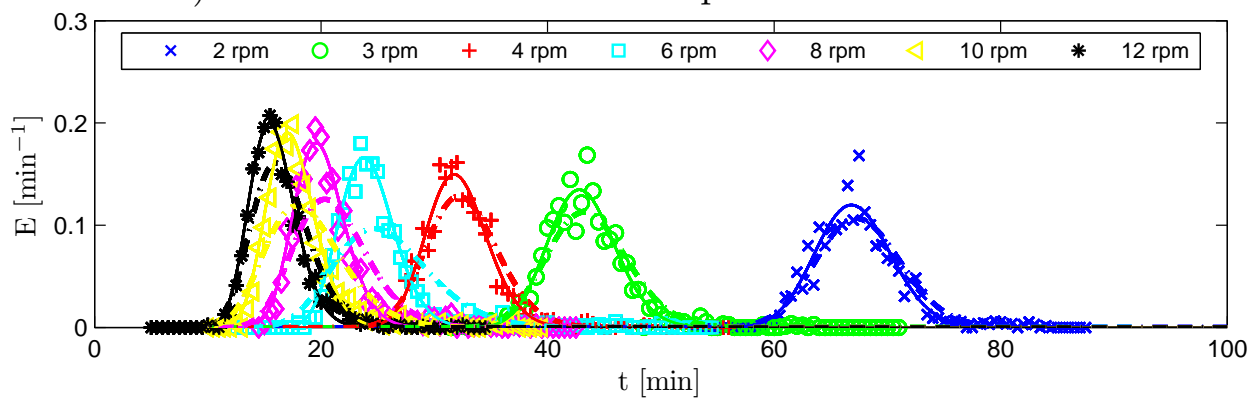

b) Influence of kiln slope - RL and broken rice

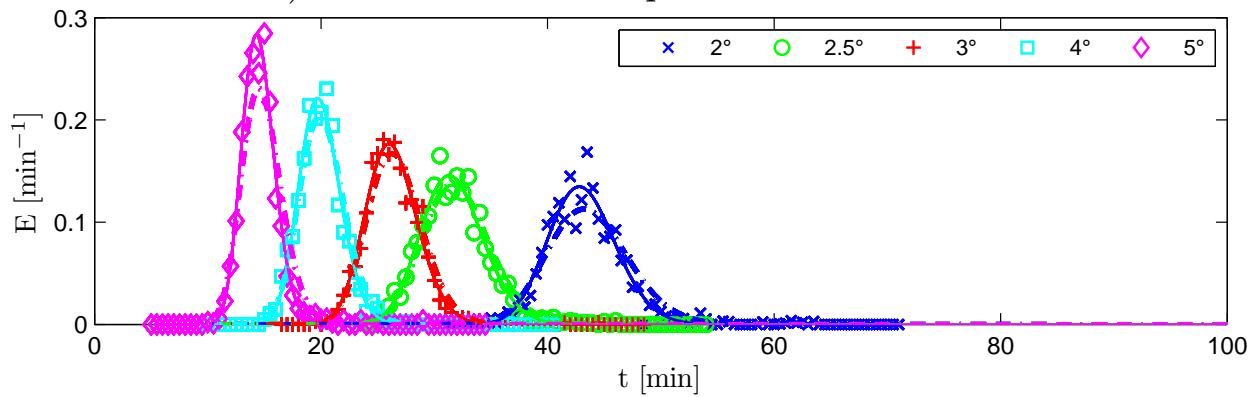

c) Influence of flow rate - RL and broken rice

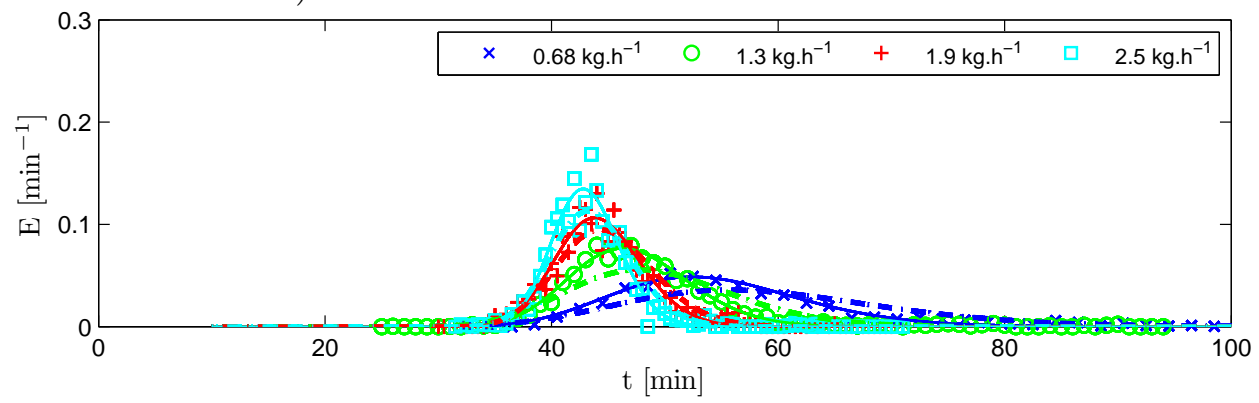

d) Influence of kiln exit dam height - RL and broken rice

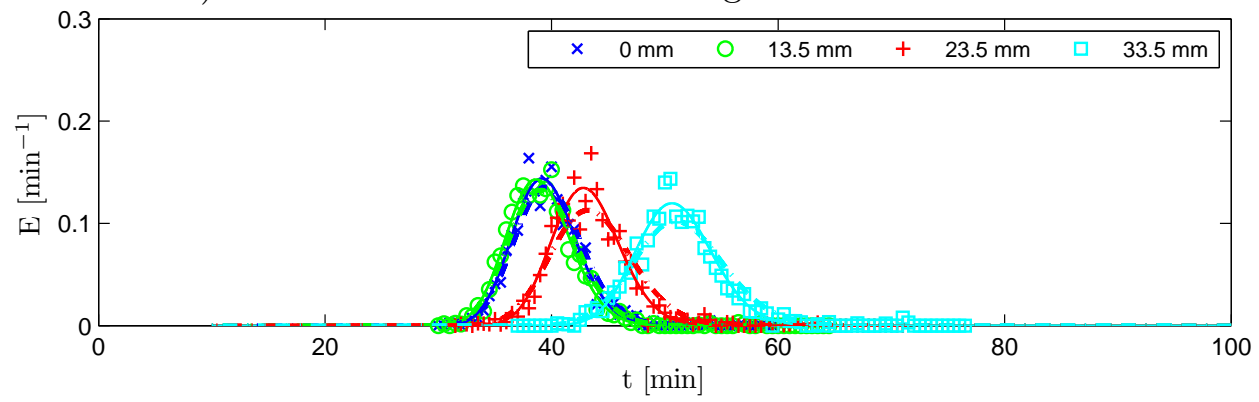

Fig. 7: Influence of operating parameters (N, S, $\dot{M}$ and exit dam height) on the RTD for the flow of broken rice, when the kiln is equipped with rectangular lifters. Solid lines represent the axial dispersion model using fitted parameters. Dashed lines represent the axial dispersion model using theoretical parameters. 

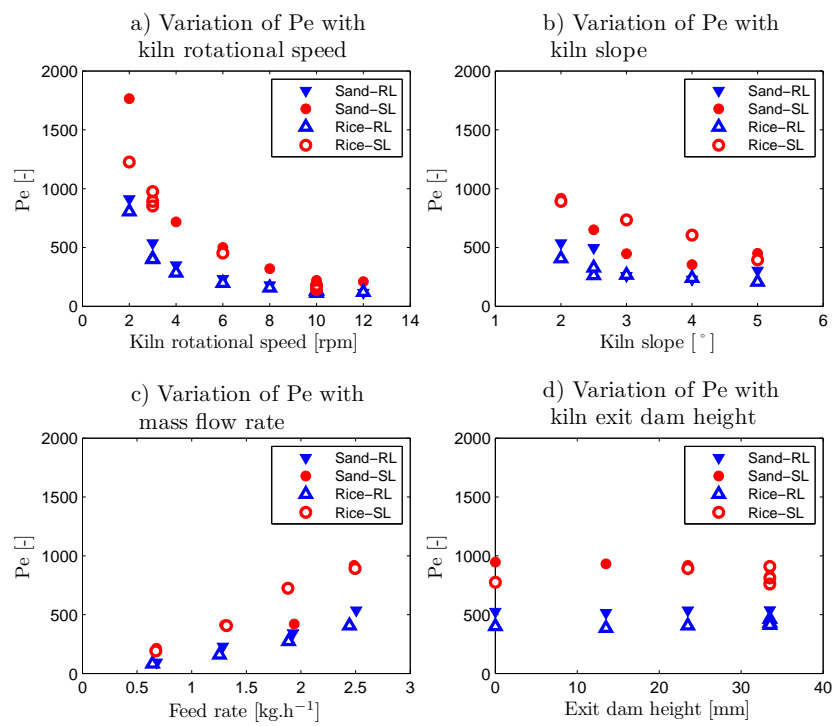

Fig. 8: Influence of operating parameters (N, S, $\dot{M}$ and exit dam height) on the experimental Peclet number for the flow of sand and broken rice, when the kiln is equipped with either straight or rectangular lifters.

flow, as is usually the case for rotary kilns. Fig.8 presents the Peclet numbers obtained by the fitting method, as function of operating parameters. The first observation is that the Peclet numbers obtained with rectangular lifters are always lower compared with those obtained while using straight lifters. This implies that rectangular lifters introduce more back-mixing into the system, confirming previous observations. The Peclet number was found to decrease with increasing kiln rotational speed and slope. However, a plateau seems to be reached in both cases for higher parameter values. As it has been previously observed while using straight lifters as well as forward and reverse spiraling lifters [10], the Peclet number increases with feed rate in the present study. It was found that the Peclet number remains quite constant, unlike Karra and Fuerstenau [8] who have detected a maximum value for the Peclet number, while varying the exit dam height. Regarding the materials used, no significant tendency was found: at similar operating conditions the Peclet numbers are in general of the same order of magnitude.

The axial dispersion coefficient was calculated using the Peclet number and the axial convective velocity in Eq.9. The effects of operating parameters on the dispersion coefficient are shown in Fig.9. It can be seen that the effect of the profile of lifters on the dispersion coefficient are highly pronounced with increasing kiln rotational speed and slightly significant for higher kiln slope or smaller flow rate. Otherwise the axial dispersion coefficient seemed to have relatively little direct dependence on the lifters shape. If the axial dispersion coefficient values with straight and rectangular lifters are sometimes closed while keeping all other operating parameters constant, experiments with rectangular lifters always have the highest value, confirming previous observations. Variations of the axial dispersion coefficient with the other parameters, namely the kiln rotational 

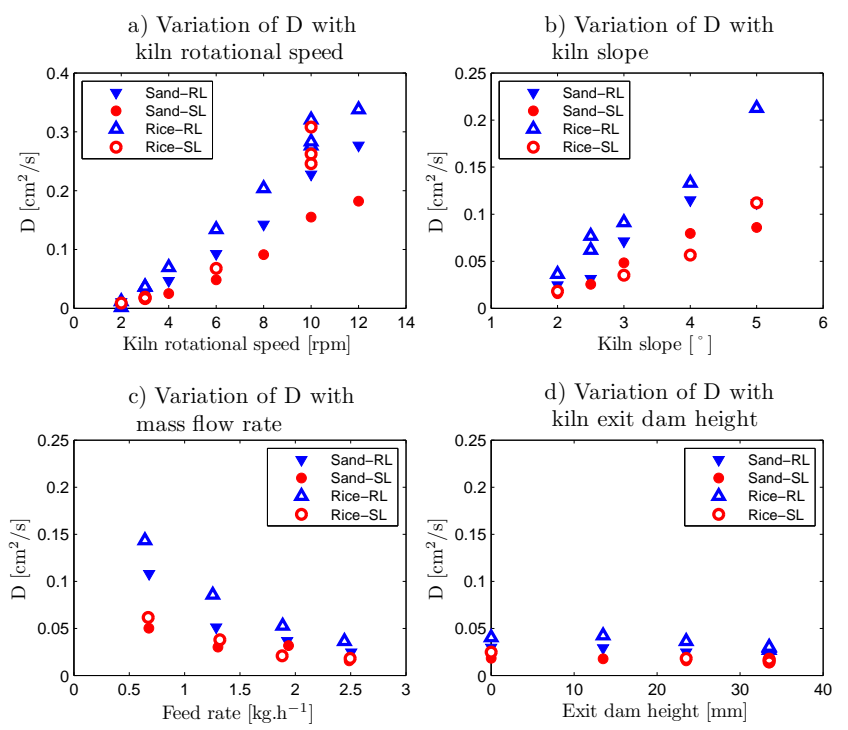

Fig. 9: Influence of operating parameters (N, S, $\dot{M}$ and exit dam height) on the experimental axial dispersion coefficient for the flow of sand and broken rice, when the kiln is equipped with either straight or rectangular lifters. The axial dispersion coefficients are obtained from the fitted Pe.

speed, the kiln slope, and the flow rate, are the opposite of those mentioned for the Peclet number: it increases with an increase in the two first $(\mathrm{N}, \mathrm{S})$ in agreement with Rutgers [6] works, and decreases with the last parameter $(\dot{M})$ contrary to Venkataraman and Fuerstenau [10] tendency for that parameter. The dispersion coefficient was quite stable when varying the exit dam height. Eventually, except for scarce cases, it appears that the axial dispersion coefficient is higher in the case of larger particles: broken rice. This may be linked to the bouncing backward or forward at the bottom of the kiln of these particles after having been cascaded from a lifter, as observed during experiments.

Some correlations intended to predict the axial dispersion coefficient have been published previously [11, 13, 44, 54].

Sai et al. [11] correlated the axial dispersion coefficient with operating parameters as follows:

$$
D / u L=0.000562 \theta_{t}^{0.79} / S^{0.67} N^{1.06} \rho_{t}^{0.25}
$$

Tracer properties were considered of major importance along with the kiln rotational speed and slope.

Sherritt et al. [44] proposed the following equation to correlate the axial dispersion coefficient with operating parameters when the hold-up volume fraction is less than 0.5:

$$
\begin{gathered}
D=0.0011\left(N / N_{c}\right)^{0.39}(i D)^{1.15}\left(d_{p}\right)^{0.46} X^{-0.43} \\
N_{c}=\frac{60}{2 \pi} \sqrt{\frac{2 g}{i D}}
\end{gathered}
$$



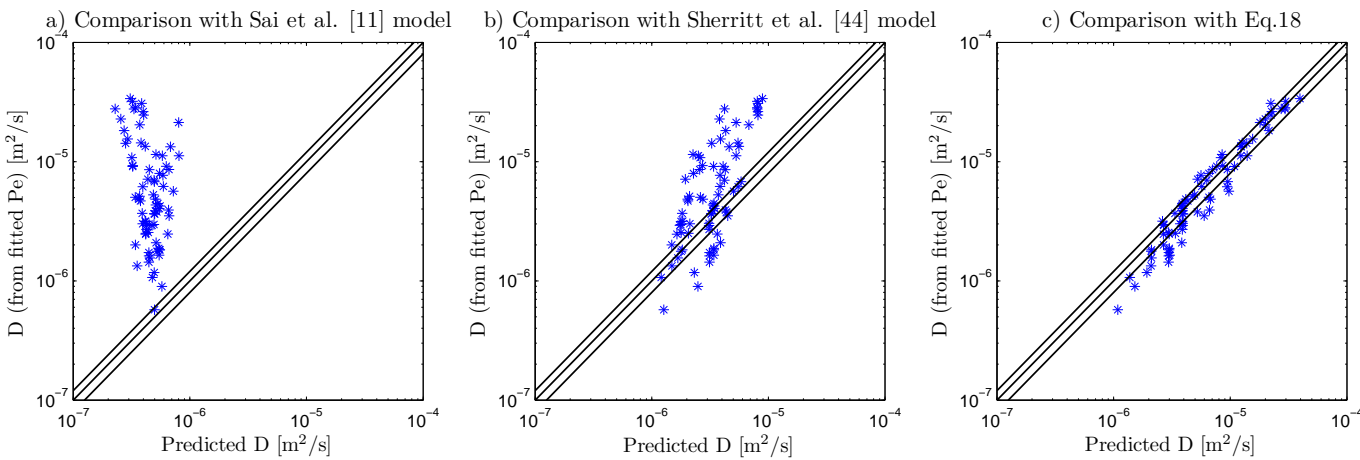

Fig. 10: Comparison of axial dispersion coefficient values obtained in the present study with predicted values from a) Sai et al. [11], b) Sherritt et al. [44], c) Present authors Eq.18. Solids lines are $\pm 20 \%$ margins.

with fitting parameters determined for all modes of bed behavior from a set of published data. $N_{c}$ is the critical speed defined in Eq.17, and $\mathrm{X}$ is the hold-up, volume fraction.

The two correlations above allow one to determine the axial dispersion coefficient. They are used to calculate the axial dispersion coefficients for the operating conditions achieved in this study. Fig.10a and Fig.10b show comparison of predictions with experimental axial dispersion coefficient values. Results do not fairly agree with the experimental data especially when using Eq.15. However both correlations results are mostly underpredicting. Therefore the axial dispersion coefficient is correlated in terms of operating parameters. Acknowledging that the geometrical properties of the kiln [44], and as discussed previously $\mathrm{N}, \mathrm{S}$, and $\dot{\mathrm{M}}$, as well as the bulk materials properties, have stronger influence on the axial dispersion coefficient, the following correlation is proposed for kiln equipped with lifters:

$$
\begin{gathered}
D=k\left(\frac{\dot{\mathrm{M}}}{\rho_{\text {bulk }}}\right)^{a}(N \cdot S)^{b}\left(\theta \cdot d_{p}\right)^{c}(L s)^{d} i D \\
L s=\frac{n_{\text {lift }}-1}{2} S_{\text {horlift }}
\end{gathered}
$$

The variables being expressed in the International System of Units, the axial dispersion coefficient D is obtained in $\mathrm{m}^{2} \cdot \mathrm{s}^{-1}$, Ls accounts for the area occupied by solid particles contained in loading lifters $\mathrm{m}^{2}, n_{\text {lift }}$ is the total number of lifters, and $S_{\text {horlift }}$ represents the section of materials in a lifter at horizontal position $\mathrm{m}^{2}$. The values of the fitted parameters $\mathrm{k}, \mathrm{a}, \mathrm{b}, \mathrm{c}$, and d were optimized using a MatLab program fitting experimental and theoretical data. Results of the calculations are presented in Table 4. Predictions are in good agreements with experimental data as shown in Fig.10c. As previously mentioned models of Sherritt et al. [44] and Sai et al. [11] appeared to be not truly realistic for the case of rotary kiln equipped with lifters while the model hereby presented should be valid and give acceptable results for that case as illustrated in Fig.10c. 
Table 4: Parameters for the axial dispersion coefficient in Eq.18.

\begin{tabular}{|c|c|c|c|}
\hline Parameters & Value & \multicolumn{2}{|c|}{ Confidence interval } \\
\hline \hline$k \times 10^{7}$ & 1.2023 & 0.1612 & 2.2434 \\
\hline $\mathrm{a}$ & -0.8714 & -0.9348 & -0.8081 \\
\hline $\mathrm{b}$ & 1.6736 & 1.6329 & 1.7144 \\
\hline $\mathrm{c}$ & 0.4349 & 0.4120 & 0.4578 \\
\hline $\mathrm{d}$ & 0.2062 & 0.1834 & 0.2290 \\
\hline
\end{tabular}

\section{Conclusions}

From the results obtained in this work, it is possible to draw the following conclusions:

- The axial dispersion model used to represent the experimental data was found to be in very good agreement with the data set. There were no particular effects of segregation or dead volume, since RTD curves do not showed extended tails. The fitted parameters were considered reasonably accurate to characterize the materials transport behavior within the system.

- The RTD curves were found to shift towards lower residence time regions with an increase in either the rotational speed, the kiln slope, or the mass flow rate, or a decrease in the exit dam height. Changes in the shape of the curve were linked to the VRT value, which remained quite stable while varying the rotational speed and exit dam height. The smaller the VRT, the higher the peak of corresponding RTD curves. Broken rice used as the largest materials has generally lower residence time than sand particles. For a given type of bulk materials the VRT are always bigger when using rectangular lifters.

- The Peclet numbers were often greater than 100, as usually observed in rotary kiln unit. They were found to be higher in the case of straight lifters. There was no significant difference between the two materials except when varying the kiln slope. The exit dam height has no incidence on the Peclet number, whereas an increase in either the rotational speed or the kiln slope induces a decrease of the Peclet number. The Peclet number increases with the feed rate. Regarding the axial dispersion coefficient, results tendencies are the inverse of those reported for the Peclet number. A correlation applicable to rotary kilns equipped with lifters is presented and showed a reasonable degree of quantitative accuracy with regard to the experimental data, compared to other published correlations.

\section{List of symbols}


$\mathrm{a}, \mathrm{b}, \mathrm{c}, \quad$ Fitted parameters

$\mathrm{d}, \mathrm{k}$

C Tracer concentration, g/g, sample conductivity $\quad \mu \mathrm{S} . \mathrm{cm}^{-1}$

$\mathrm{Cv}$ Coefficient of variation -

D Axial dispersion $\mathrm{m}^{2} \cdot \mathrm{s}^{-1}$ coefficient

$\mathrm{d}_{p} \quad$ Average particle size $\quad \mathrm{m}$

$\mathrm{E}(\mathrm{t})$ Distribution function $\mathrm{min}^{-1}$

$\mathrm{E}(\theta) \quad$ Dimensionless distribution function

g Gravitational

$\mathrm{m} \cdot \mathrm{s}^{-2}$ acceleration

iD Kiln internal diameter m

L Kiln Length m

Ls Area occupied by solid $\mathrm{m}^{2}$ particles contained in loading lifters

MFR Mean Flow rate kg.h $\mathrm{h}^{-1}$

MRT Mean residence time min

$\mathrm{N} \quad$ Kiln rotational speed rpm

$\mathrm{N}_{c} \quad$ Critical speed

NL No lifters

$\mathrm{n}_{\text {lift }} \quad$ Total number of lifters

$\mathrm{N}_{S} \quad$ Total number of samples

$\mathrm{Pe} \quad$ Peclet number

RL Rectangular lifters

rpm Rotation per minute

RTD Residence Time

Distribution

S Kiln slope

SL Straight lifters

S ${ }_{\text {horlift }}$ Area covered by solid particles in a lifter at horizontal position

std Standard deviation

t Time

$\min$

$\overline{\mathrm{t}} \quad \mathrm{MRT}$

$\min$

u Velocity

$\mathrm{m} . \mathrm{s}^{-1}$

V Lifter volumetric

$\mathrm{cm}^{3}$

hold-up

VRT Variance of the RTD $\min ^{2}$

$\mathrm{X}$ Hold-up volume fraction

z Dimensionless axial

position 


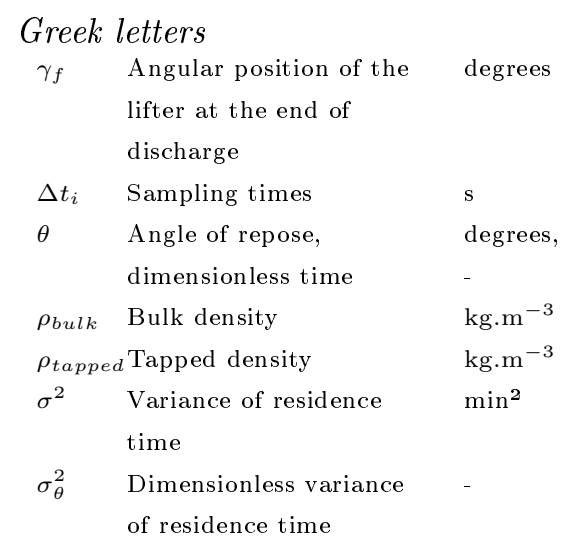

$\begin{array}{cl}\text { Subscripts } \\ \text { NL } & \text { No lifters } \\ \text { oo } & \text { Open-open } \\ \text { RL } & \text { Rectangular lifters } \\ \text { SL } & \text { Straight lifters } \\ \text { t } & \text { Tracer }\end{array}$

\section{Reference}

[1] J. D. Sullivan, C. G. Maier, O. C. Ralston, Passage of solid particles through rotary cylindrical kilns, Govt. print. off., Washington, 1927.

[2] C. F. Prutton, C. O. Miller, W. H. Schuette, Factors Influencing the Performance of Rotary Dryers, American Institute of Chemical Engineers 38 (1942) 841-864.

[3] W. C. Saeman, Passage of solids through rotary kilns. Factors affecting time of passage, Chemical Engineering Progress 47 (1951) 508-514.

[4] H. Kramers, P. Croockewit, The passage of granular solids through inclined rotary kilns, Chemical Engineering Science 1 (6) (1952) 259-265.

[5] F. Schofield, P. Glikin, Rotary dryers and coolers for granular fertilizers, Transactions of the Institution of Chemical Engineers 40 (1962) 183-190.

[6] R. Rutgers, Longitudinal mixing of granular material flowing through a rotating cylinder: Part II. Experimental, Chemical Engineering Science 20 (12) (1965) 1089-1100.

[7] A.-Z. Abouzeid, T. Mika, K. Sastry, D. Fuerstenau, The influence of operating variables on the residence time distribution for material transport in a continuous rotary drum, Powder Technology 10 (6) (1974) 273-288.

[8] V. Karra, D. Fuerstenau, Material transport in a continuous rotary drum. Effect of discharge plate geometry, Powder Technology 16 (1) (1977) 23-28.

[9] M. Hehl, H. Kroger, H. Helmrich, K. Schugerl, Longitudinal mixing in horizontal rotary drum reactors, Powder Technology 20 (1) (1978) 29-37.

[10] K. Venkataraman, D. Fuerstenau, Effect of lifter shape and configuration on material transport part I: In rotating drums, Powder Technology 46 (1) (1986) 23-32.

[11] P. S. T. Sai, G. D. Surender, A. D. Damodaran, V. Suresh, Z. G. Philip, K. Sankaran, Residence time distribution and material flow studies in a rotary kiln, Metallurgical Transactions B 21 (6) (1990) 1005-1011. 
[12] E. Lebas, F. Hanrot, D. Ablitzer, J.-L. Houzelot, Experimental study of residence time, particle movement and bed depth profile in rotary kilns, The Canadian Journal of Chemical Engineering 73 (2) (1995) 173-180.

[13] H. M. Ang, M. O. Tade, M. W. Sze, Residence Time Distribution for a Cold Model Rotary Kiln, vol. 1, The AusIMM, 1998.

[14] K. S. Hatzilyberis, G. P. Androutsopoulos, An Rtd Study for the Flow of Lignite Particles Through a Pilot Rotary Dryer Part Ii: Flighted Drum Case, Drying Technology 17 (4-5) (1999) 759-774.

[15] K. S. Hatzilyberis, G. P. Androutsopoulos, An Rtd Study for the Flow of Lignite Particles Through a Pilot Rotary Dryer Part I; Bare Drum Case, Drying Technology 17 (4-5) (1999) 745-757.

[16] O. S. Sudah, A. Chester, J. Kowalski, J. Beeckman, F. Muzzio, Quantitative characterization of mixing processes in rotary calciners, Powder Technology 126 (2) (2002) 166-173.

[17] S.-Q. Li, J.-H. Yan, R.-D. Li, Y. Chi, K.-F. Cen, Axial transport and residence time of MSW in rotary kilns: Part I. Experimental, Powder Technology 126 (3) (2002) 217-227.

[18] W. Z. Chen, C. H. Wang, T. Liu, C. Y. Zuo, Y. H. Tian, T. T. Gao, Residence time and mass flow rate of particles in carbon rotary kilns, Chemical Engineering and Processing: Process Intensification 48 (4) (2009) 955-960.

[19] A.-Z. M. Abouzeid, D. W. Fuerstenau, Flow of Non-Homogeneous Particulates in Rotating Drums, KONA Powder and Particle Journal (28) (2010) 155-166.

[20] Y. Gao, A. Vanarase, F. Muzzio, M. Ierapetritou, Characterizing continuous powder mixing using residence time distribution, Chemical Engineering Science 66 (3) (2011) 417-425.

[21] S. Bensmann, A. Subagyo, P. Walzel, Residence Time Distribution of Segregating Sand Particles in a Rotary Drum, Particulate Science and Technology 28 (4) (2010) 319-331.

[22] C. Baker, The Design of Flights in Cascading Rotary Dryers, Drying Technology 6 (4) (1988) 631-653.

[23] A. Matchett, M. Sheikh, An Improved Model of Particle Motion in Cascading Rotary Dryers, Chemical Engineering Research and Design 68 (1990) 139-148.

[24] R. G. Sherritt, R. Caple, L. A. Behie, A. K. Mehrotra, The movement of solids through flighted rotating drums. Part i: Model formulation, The Canadian Journal of Chemical Engineering 71 (3) (1993) 337-346.

[25] R. G. Sherritt, R. Caple, L. A. Behie, A. K. Mehrotra, The movement of solids through flighted rotating drums. Part II solids-gas interaction and model validation, The Canadian Journal of Chemical Engineering 72 (2) (1994) 240-248.

[26] F. Wang, I. Cameron, J. Litster, V. Rudolph, A Funtadamental Study on Particle Transport Through Rotary Dryers for Flight Design and System Optimisation, Drying Technology 13 (5-7) (1995) 1261-1278

[27] M. H. Lisboa, D. S. Vitorino, W. B. Delaiba, J. R. D. Finzer, M. A. S. Barrozo, A study of particle motion in rotary dryer, Brazilian Journal of Chemical Engineering 24 (3) (2007) 365-374.

[28] K. Cronin, M. Catak, J. Bour, A. Collins, J. Smee, Stochastic modelling of particle motion along a rotary drum, Powder Technology 213 (1-3) (2011) 79-91.

[29] O. Ajayi, M. Sheehan, Design loading of free flowing and cohesive solids in flighted rotary dryers, Chemical Engineering Science 73 (2012) 400-411.

[30] K. R. Sunkara, F. Herz, E. Specht, J. Mellmann, R. Erpelding, Modeling the discharge characteristics of rectangular flights in a flighted rotary drum, Powder Technology 234 (2013) 107-116.

[31] K. R. Sunkara, F. Herz, E. Specht, J. Mellmann, Influence of flight design on the particle distribution of a flighted rotating drum, Chemical Engineering Science 90 (2013) 101-109.

[32] Y. Gao, F. J. Muzzio, M. G. Ierapetritou, A review of the Residence Time Distribution (RTD) applications in solid unit operations, Powder Technology 228 (2012) 416-423.

[33] A. D. Martin, Interpretation of residence time distribution data, Chemical engineering science 55 (2000) 5907-5917.

[34] C. Duchesne, J. Thibault, C. Bazin, Modeling of the Solids Transportation within an Industrial Rotary Dryer: A Simple Model, Engineering Chemistry Research 35 (7)

[35] J. Mu, D. D. Perlmutter, The mixing of Granular solids in a rotary cylinder, AIChE Journal 26 (6) (1980) 928-934.

[36] M. E. Sheehan, P. A. Schneider, A. Monro, S. Vigh, Transportation and axial dispersion of sugar in flighted rotary dryers., PK Editorial Services Pty Ltd, 469-474, 2002.

[37] L. Dinesh V, P. S. T. Sai, A Model for Residence Time Distribution of Solids in a Rotary Kiln, The Canadian Journal of Chemical Engineering 82 (2) (2004) 392-398.

[38] M. Sheehan, P. Britton, P. Schneider, A model for solids transport in flighted rotary dryers based on physical considerations, Chemical Engineering Science 60 (15) (2005) 4171-4182. 
[39] P. Britton, M. Sheehan, P. Schneider, A physical description of solids transport in flighted rotary dryers, Powder Technology 165 (3) (2006) 153-160.

[40] P. Thammavong, M. Debacq, S. Vitu, M. Dupoizat, Experimental Apparatus for Studying Heat Transfer in Externally Heated Rotary Kilns, Chemical Engineering \& Technology 34 (5) (2011) $707-717$.

[41] O. Levenspiel, Chemical reaction engineering, Wiley, 1999.

[42] P. Danckwerts, Continuous flow systems. Distribution of residence times, Chemical Engineering Science 50 (24) (1952) 3857-3866.

[43] H. Risken, The Fokker-Planck equation: methods of solution and applications, Springer, Berlin, 1996

[44] R. G. Sherritt, J. Chaouki, A. K. Mehrotra, L. A. Behie, Axial dispersion in the three-dimensional mixing of particles in a rotating drum reactor, Chemical Engineering Science 58 (2) (2003) 401-415.

[45] S. Das Gupta, D. Khakhar, S. Bhatia, Axial transport of granular solids in horizontal rotating cylinders. Part 1: Theory, Powder Technology 67 (2) (1991) 145-151.

[46] H. A. Thomas, McKee, Longitudinal mixing in aeration tanks, Sewage Works Journal 16 (1) (1944) $42-55$.

[47] A. S. Bongo Njeng, S. Vitu, M. Clausse, J.-L. Dirion, M. Debacq, Effect of Lifters Shape and Operating Parameters on the Flow of Materials in a Pilot Rotary Kiln : Part II. Experimental Hold-up and Mean Residence Time Modeling, Powder Technology (Submitted).

[48] M. Debacq, S. Vitu, D. Ablitzer, J.-L. Houzelot, F. Patisson, Transverse motion of cohesive powders in flighted rotary kilns: experimental study of unloading at ambient and high temperatures, Powder Technology 245 (2013) 56-63.

[49] L. M. Grajales, N. M. Xavier, J. P. Henrique, J. C. Thomeo, Mixing and motion of rice particles in a rotating drum, Powder Technology 222 (2012) 167.

[50] B. Chaudhuri, F. J. Muzzio, M. S. Tomassone, Experimentally validated computations of heat transfer in granular materials in rotary calciners, Powder Technology 198 (1) (2010) 6-15.

[51] J. Mellmann, The transverse motion of solids in rotating cylinders-forms of motion and transition behavior, Powder Technology 118 (3) (2001) 251-270.

[52] S. Friedman, W. Marshall, Studies in rotary drying part I-holdup and dusting, Chemical Engineering Progress 45 (8) (1949) 482-493.

[53] J.-P. Pan, T.-J. Wang, J.-J. Yao, Y. Jin, Granule transport and mean residence time in horizontal drum with inclined flights, Powder Technology 162 (1) (2006) 50-58.

[54] L.-T. Fan, Y.-K. Ahn, Axial dispersion of solids in rotary solid flow systems, Applied Scientific Research 10 (1) (1961) 465-470. 